\title{
Hematuria como primer signo del condrosarcoma de pelvis
}

\section{Hematuria as the first sign of pelvic chondrosarcoma}

\author{
Salvador-Marín J, ${ }^{*}$ Izquierdo-Plazas L, ${ }^{*}$ Ausina-Gómez S, ${ }^{*}$ López-López C, ${ }^{\ddagger}$ Castro-Copete MC ${ }^{\S}$ \\ Hospital Universitario Sant Joan d'Alacant. Alicante.
}

\begin{abstract}
RESUMEN. El condrosarcoma es un tumor maligno que afecta con frecuencia la pelvis y su sintomatología es inespecífica e insidiosa. Describimos el caso de un condrosarcoma de la rama iliopubiana derecha en un varón de 62 años cuyo primer signo de aparición fue una hematuria macroscópica esporádica, relacionada con esfuerzos y de cuatro meses de evolución. Tras ser estudiado por el servicio de urología mediante cistoscopía con biopsia de tumoración en pared vesical se aprecian células de estirpe condral. Tras posterior estudio con pruebas de imagen se diagnostica condrosarcoma de bajo grado con invasión de la vejiga, por lo que es valorado en el comité de tumores musculoesqueléticos y se realiza un abordaje multidisciplinar mediante exéresis en bloque y reconstrucción del suelo pélvico. Actualmente el paciente continúa asintomático.
\end{abstract}

Palabras clave: Condrosarcoma de pelvis, hematuria, tratamiento multidisciplinar, resección en bloque.

\section{Introducción}

El condrosarcoma representa aproximadamente $20 \%$ de los tumores óseos malignos, siendo el segundo más frecuente tras el osteosarcoma. Juntos constituyen $0.2 \%$ de todas las neoplasias malignas. Su ubicación más frecuente es la pelvis. ${ }^{1,2}$

La sintomatología es inespecífica dependiendo de su localización (osteoartritis, dolor, inestabilidad articular) y
ABSTRACT. Chondrosarcoma is a malignant tumor which often affects the pelvic ring and its symptomathology is non-specific and insidious. We display a case of a right iliopubic branch chondrosarcoma in a 62-year-old male whose first sing was a four-year history of sporadic macroscopic haematuria, related to efforts. After being studied by the Urology Department by cystoscopy and biopsy of bladder tumor, chondral cells were appreciated. Further study with imaging tests diagnosed low-grade chondrosarcoma with bladder infringement. The case is assessed by Musculoskeletal Tumors Committee and a multidisciplinary approach is carried out through en bloc resection and pelvic floor reconstruction. Currently the patient remains asymptomatic.

Keywords: Pelvic chondrosarcoma, haematuria, multidisciplinary approach, en bloc resection.

su aparición es insidiosa, lo que ocasiona gran dificultad y demora en el diagnóstico. Cuando el tumor se sitúa en la pelvis puede presentarse inflamación o molestias con la micción o defecación debido al desplazamiento de la anatomía normal de la zona. ${ }^{3}$

El gran volumen y extensión, la ausencia de barreras anatómicas y la cercanía de vísceras abdominales en la pelvis hacen que las técnicas de resección y reconstrucción

\footnotetext{
* Servicio de Cirugía Ortopédica y Traumatología. Unidad de Tumores Musculoesqueléticos.

* Servicio de Urología.

§ Servicio de Radiodiagnóstico.

Hospital Universitario Sant Joan d'Alacant. Alicante.

Correspondencia:

Dr. Jorge Salvador Marín

Hospital Universitario Sant Joan d'Alacant

Carretera Nacional 332, Alacant-Valencia, s/n, C.P. 03550, Sant Joan d'Alacant, Alacant.

E-mail: salvadormarinj@gmail.com
} 
sean complejas. Esto, junto a su importancia en cuanto a la capacidad funcional y la frecuente demora en el diagnóstico ensombrece el pronóstico de estas lesiones.

El objetivo de nuestro artículo es describir el inusual caso de un condrosarcoma pélvico cuya manifestación inicial fue la hematuria en un varón de 62 años.

\section{Caso clínico}

Varón de 62 años, fumador de 20 paquetes-año, con antecedentes personales de artritis reumatoide en tratamiento con certolizumab que es valorado en atención primaria por presentar episodios esporádicos de hematuria macroscópica relacionados con el ejercicio, de cuatro meses de evolución. A la exploración física presenta molestias a la palpación en fosa ilíaca derecha sin masas asociadas. Tras realización de análisis de sangre incluyendo antígeno prostático específico (PSA) y ecografía de aparato urinario y vejiga, que informa de «próstata heterogénea y mal definida, con calcificaciones y aumentada de volumen en unos $60 \mathrm{~cm}^{3} »$, es remitido a urología. Se realiza una cistoscopía en la que se aprecia «litiasis de $1.5-2 \mathrm{~cm}$ y una neoformación papilar de aspecto superficial $<1 \mathrm{~cm}$ en proximidad del meato ureteral derecho», por lo que se decide llevar a cabo una cistolitotricia endoscópica y resección transuretral vesical (RTU). La liberación de la «litiasis vesical» se describe como «aspecto de tumor calcificado» y se aprecia un «tumor vesical extenso sólido de pared anterior y fondo calcificado en superficie». Ante estos hallazgos, se solicita una radiografía (Rx) de abdomen (Figura 1) y se envían muestras a anatomía patológica (AP). Posteriormente se realiza tomografía axial computarizada (TAC) abdomino-

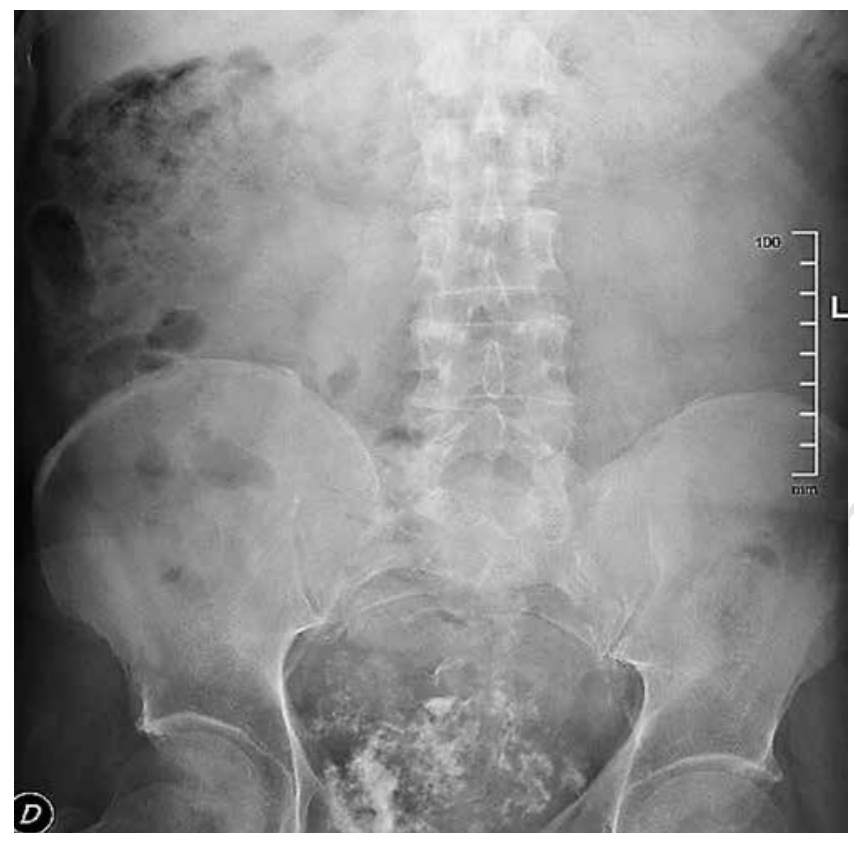

Figura 1: Radiografía de abdomen que muestra calcificaciones difusas intrapélvicas.
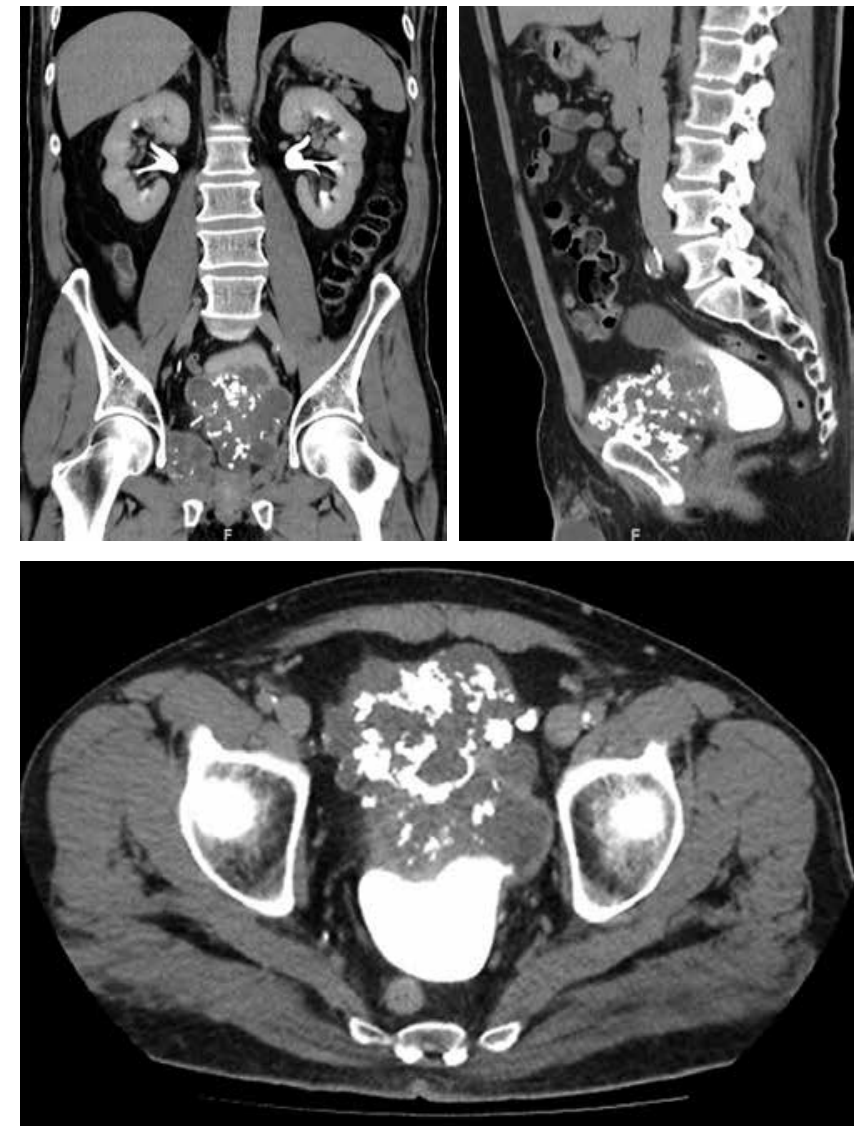

Figura 2: Tomografía axial computarizada abdominopélvico con contraste.

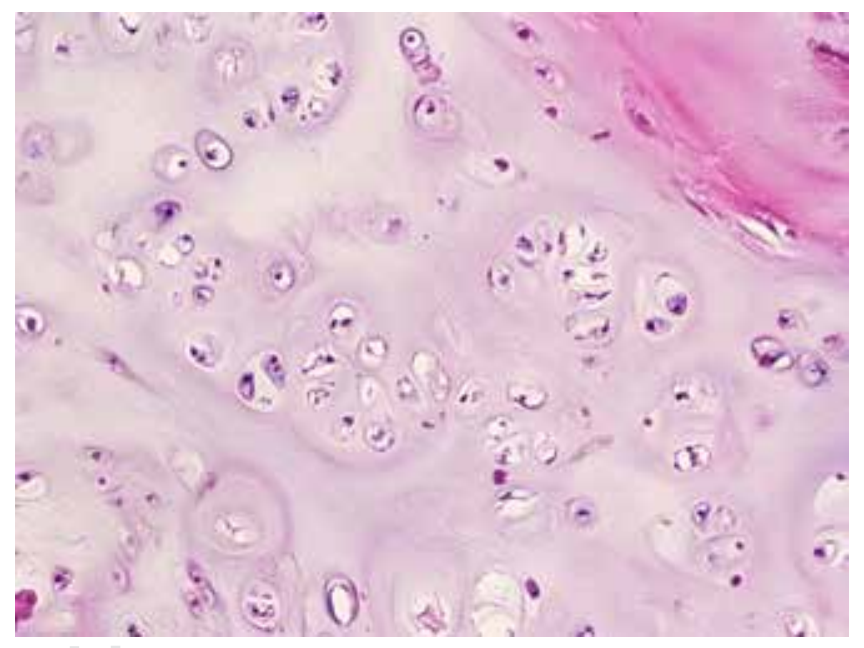

Figura 3: Células de estirpe condral en la muestra de anatomía: morfología lobulada, algunas binucleadas y nucléolos prominentes. Citoplasma claro, agrupación en lagunas y amplia matriz extracelular.

pélvica con contraste (Figura 2), que informa de «masa infiltrante exofítica que afecta a la vertiente anteroinferior de la vejiga con signos sugestivos de probable infiltración de la rama iliopubiana derecha y del músculo obturador homolateral, contactando asimismo con la vertiente anterior de la próstata, sin plano de separación grasa. Neoplasia 

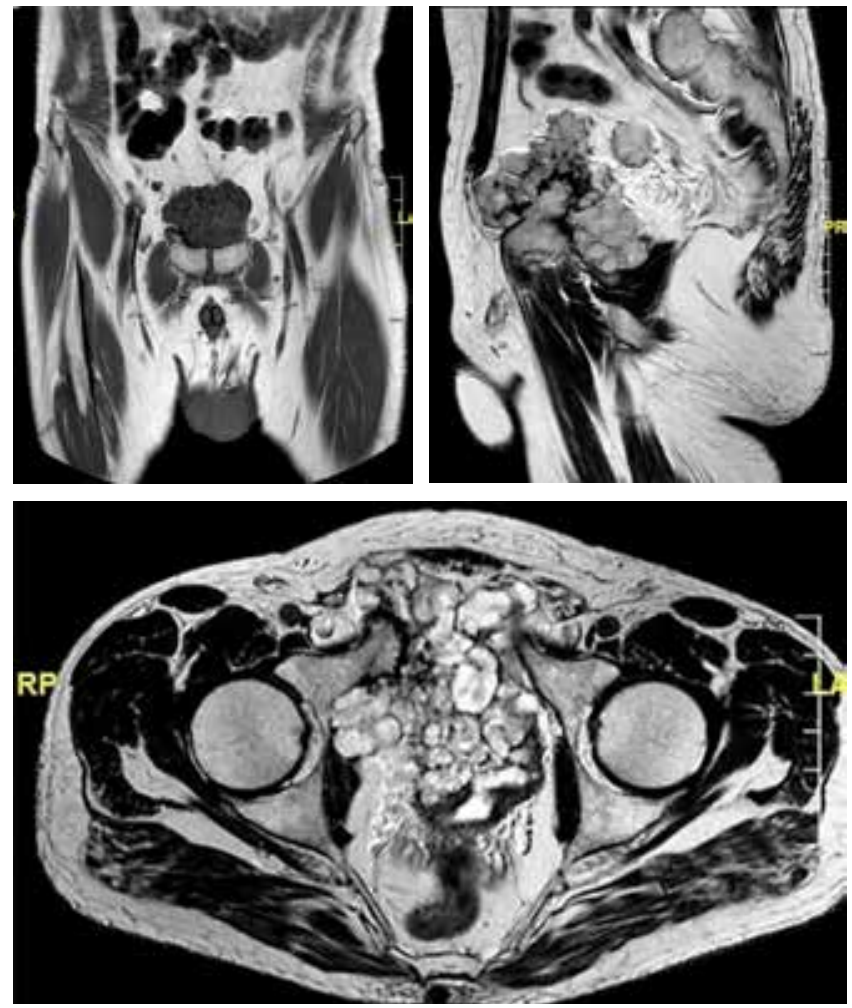

Figura 4: Cortes T1-T2W de resonancia magnética nuclear anteroposterior, sagital y axial.

vesical infiltrante (T4) con adenopatía sospechosa en cadena ilíaca externa derecha, sin lesiones de tracto urinario superior ni a distancia».

Sin embargo, el estudio de las muestras por anatomía patológica informa de:

- «Neoplasia papilar urotelial de bajo grado de malignidad»: infiltración por condrosarcoma bajo grado (Figura 3).

- Calcificación de tumor: tejido cartilaginoso calcificado (Figura 3).
Ante la discordancia en los informes de las pruebas diagnósticas se completa el estudio con una resonancia magnética nuclear (RMN), que informa de «tumoración pélvica de $10 \mathrm{~cm}$ de diámetro mayor con origen en la rama iliopúbica derecha que por sus características es compatible con un condrosarcoma que infiltra la pared anterior de la vejiga y el músculo obturador interno derecho» (Figuras 4 y 5 ).

En ese momento el paciente es derivado al servicio de cirugía ortopédica y traumatología (COT) y tras valoración por el comité de tumores musculoesqueléticos (CTME) se realiza un estudio de extensión mediante TAC de tórax y gammagrafía ósea 99mTc-HMDP de cuerpo entero, la cual es negativa para enfermedad metastásica a distancia (Figura 6). Se decide intervención quirúrgica con el diagnóstico de condrosarcoma en zona 3 de Enneking ${ }^{6}$ (Figura 7). Se realiza exéresis ampliada de la tumoración con cistectomía radical (Figuras 8 y 9) y reconstrucción del suelo pélvico con malla sin reconstrucción ósea junto a cirujanos urológicos y del aparato digestivo.

El diagnóstico histopatológico fue condrosarcoma grado 1 que infiltra focalmente la pared muscular de la vejiga urinaria, con márgenes quirúrgicos libres de tumor (Figura 10).

El postoperatorio inmediato cursó en UCI dado el elevado tiempo de la intervención y fue dado de alta a los siete días. Durante el postoperatorio tardío se produjo un seromainfección de la herida quirúrgica que requirió ingreso, que se resolvió con curas y antibioterapia y una infección urinaria que fue tratada mediante antibioterapia y recambio del doble $\mathrm{J}$ dejado como tutor de la ureterostomía cutánea.

Se pautó carga inmediata y el seguimiento en consultas externas cursa sin incidencias. A los seis meses de seguimiento se realizó TAC de control sin evidencia de extensión a distancia de la enfermedad.

Actualmente a los 20 meses de seguimiento el paciente está asintomático y camina con normalidad. Las pruebas de imagen no han mostrado recidivas.
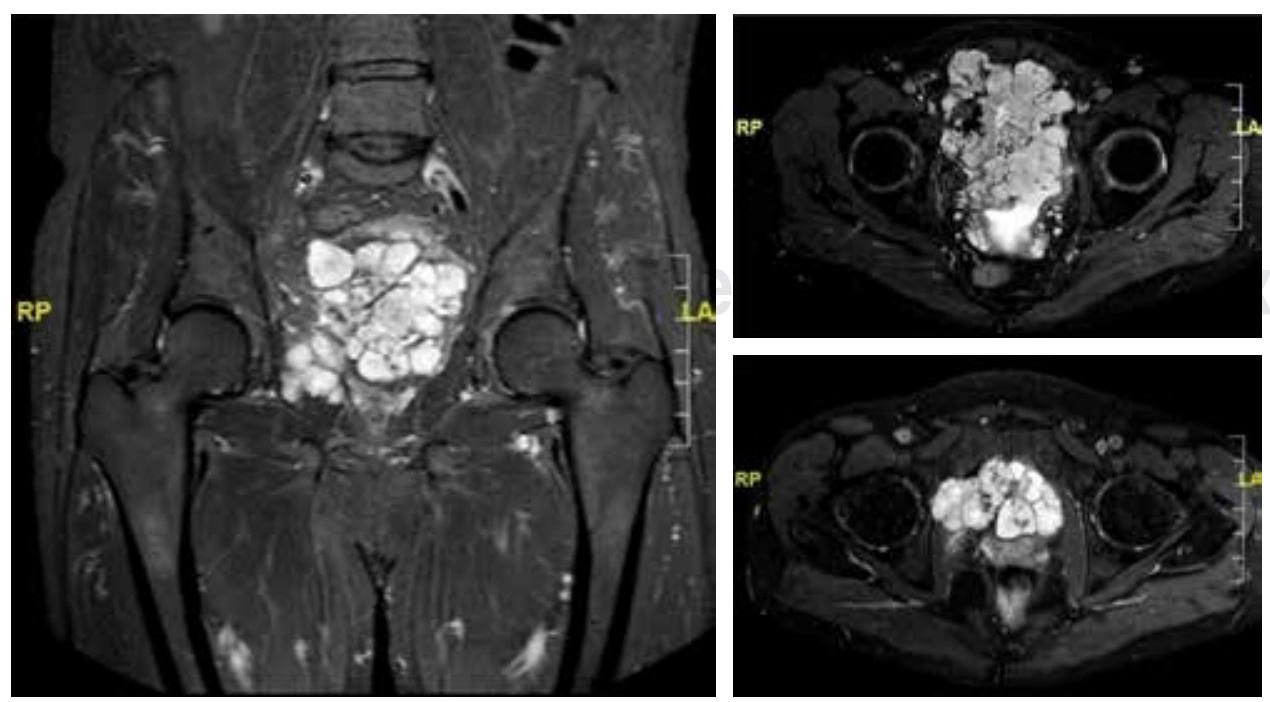

Figura 5:

Cortes STIR de resonancia magnética nuclear anteroposterior y axial. STIR: Short Tau Inversion Recovery. 

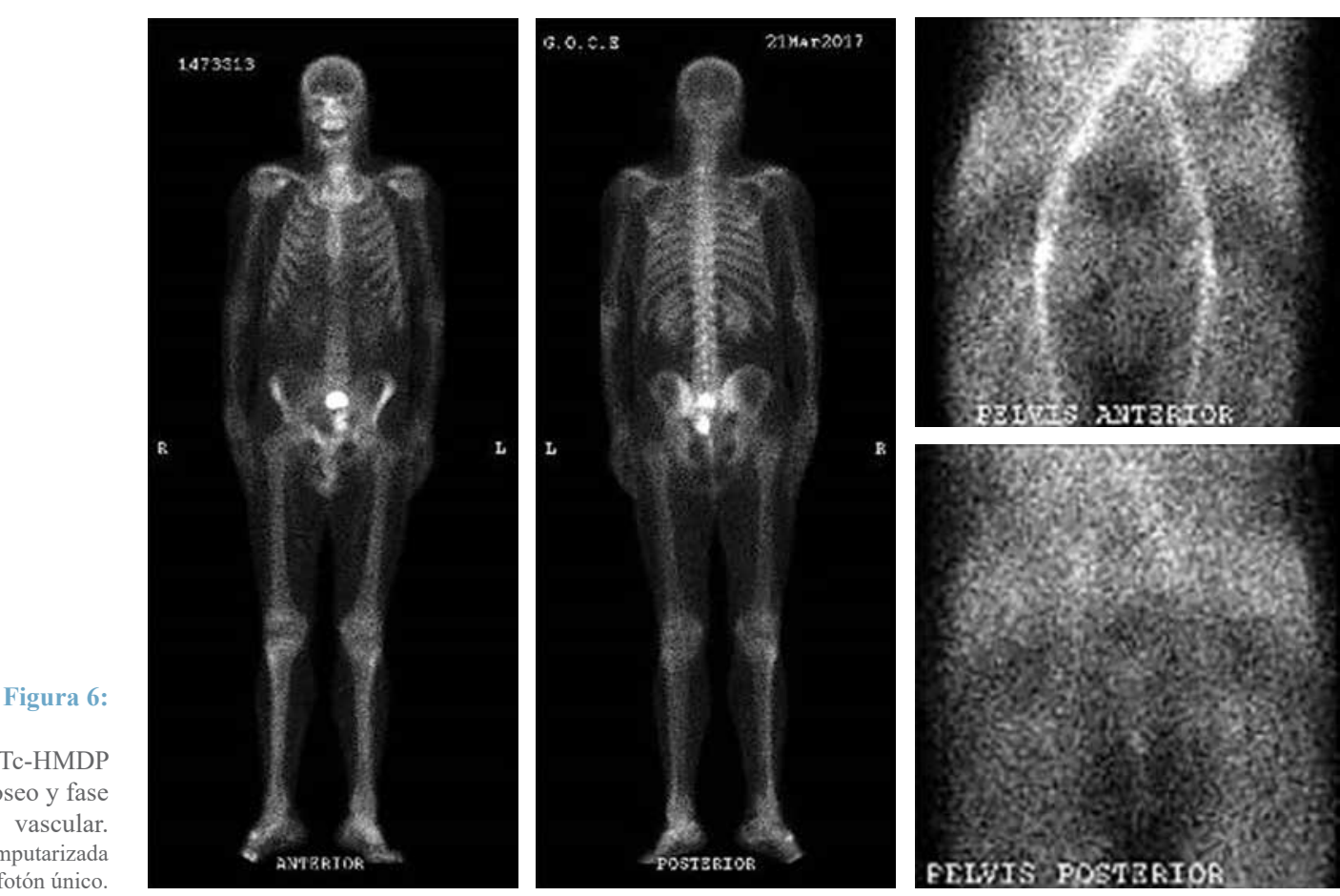

Gammagrafía ósea 99mTc-HMDP de cuerpo entero. SPECT óseo y fase

SPECT $=$ Tomografía computarizad por emisión de fotón único.

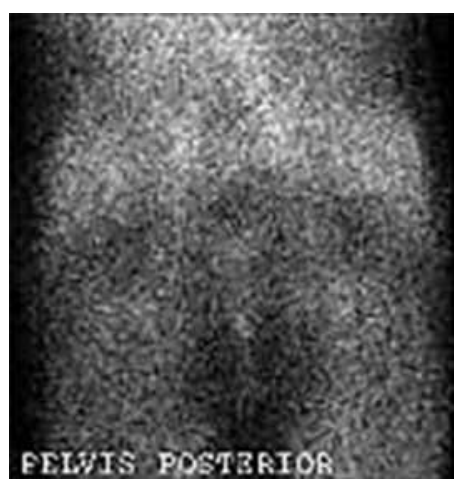

\section{Discusión}

Los condrosarcomas son tumores malignos constituidos por células de fenotipo cartilaginoso que muestran un patrón histológico lobulado. Son un grupo heterogéneo con características morfológicas y comportamientos clínicos diversos. Tienen su pico de aparición alrededor de la sexta década de la vida y, aunque su etiología más frecuente es la primaria, pueden ser secundarios a exóstosis o encondromatosis múltiple (enfermedad de Ollier). Su localización más frecuente es la pelvis (30\%), más comúnmente el isquion, seguido del fémur proximal y húmero proximal. ${ }^{1,}$

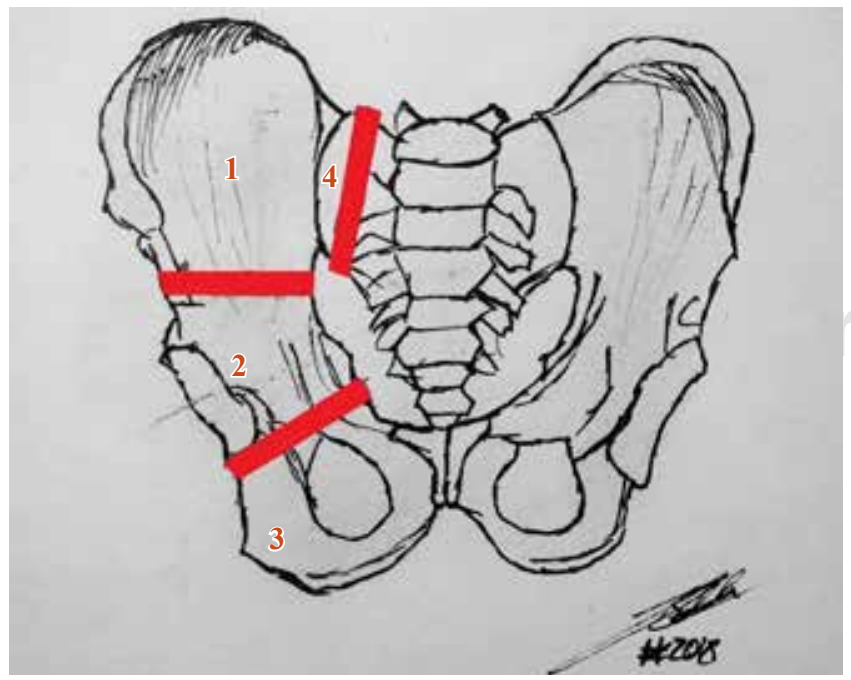

Figura 7: Clasificación de Enneking y Dunham.

El diagnóstico de sospecha es difícil dada la sintomatología inespecífica y el curso insidioso. La hematuria como primer signo de este tumor es extremadamente rara, habiéndose documentado en otros casos de tumores en la pelvis renal.

La radiología simple (radiografía y ecografía) son los pilares del algoritmo diagnóstico, siendo sus características radiológicas la matriz cartilaginosa, las calcificaciones en «palomita de maíz» y los bordes mal definidos (Figura 1).

La TAC y la RMN son útiles para la visualización de la ventana ósea y partes blandas respectivamente, además del estudio de las relaciones anatómicas del tumor para la planificación preoperatoria. Por otra parte, el estudio de extensión se compone de TAC toraco-abdomino-pélvico con contraste y gammagrafía ósea de tres fases. El patrón de oro del diagnóstico es la biopsia, que además ayuda a establecer el pronóstico de la lesión estadificando el tumor según su grado de malignidad. ${ }^{1} \mathrm{La}$

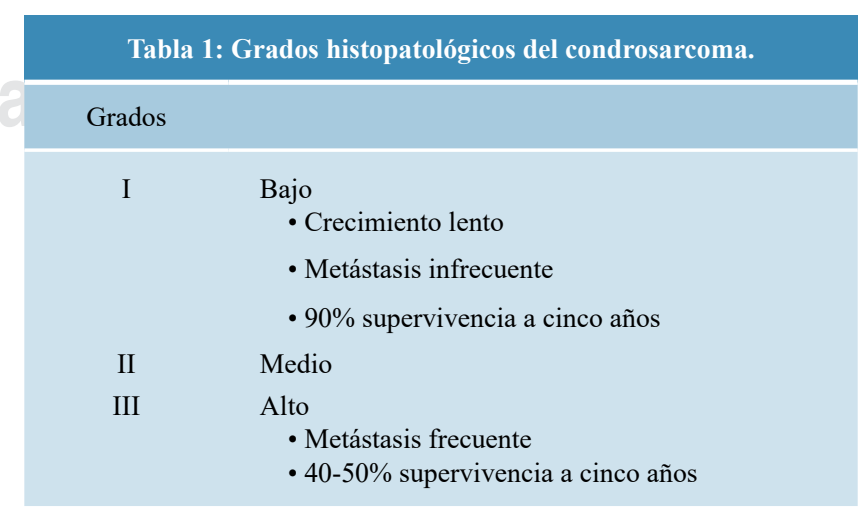


Figura 8:

Imágenes de la pieza quirúrgica: tumoración en rama iliopúbica dere-

cha que invade vejiga urinaria, de

$17 \times 14 \times 10 \mathrm{~cm}$ de aspecto nodular cartilaginoso.
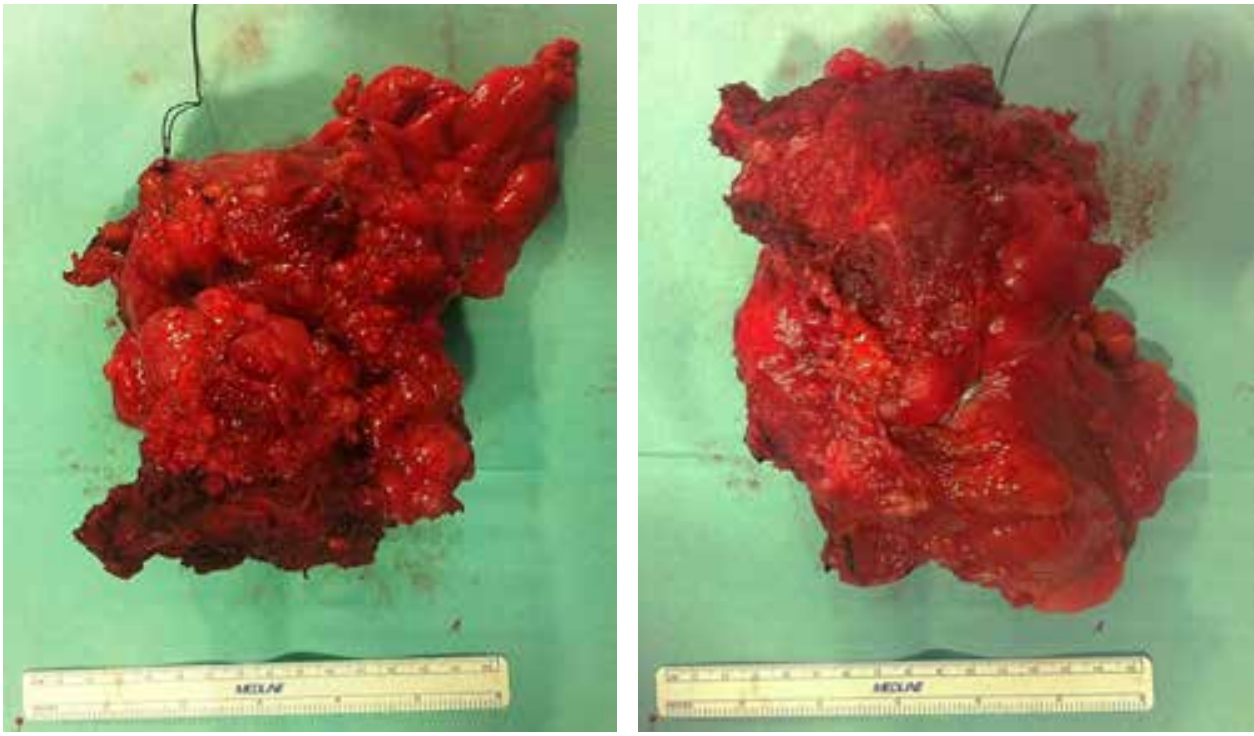

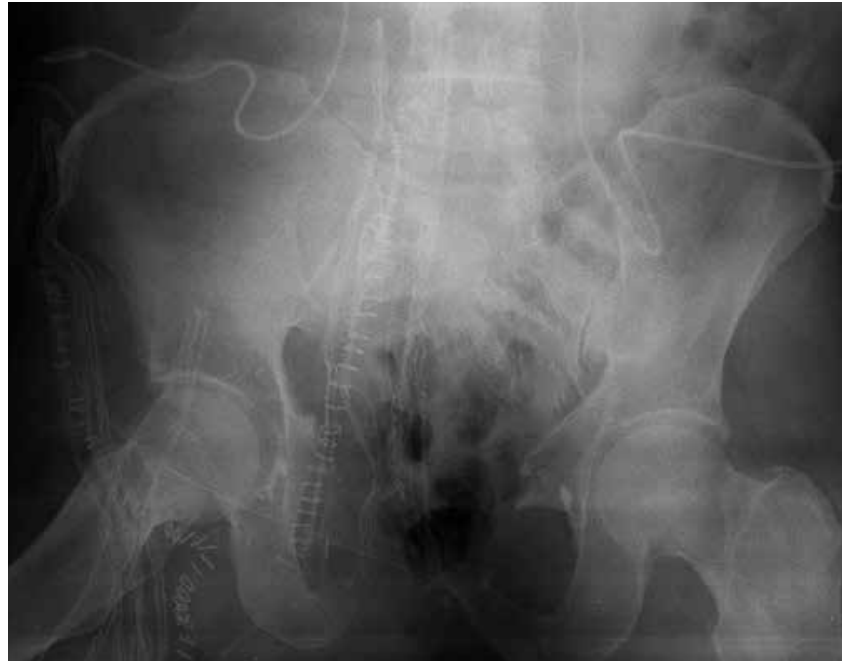

Figura 9: Radiografía postoperatoria del paciente. Apréciese la resección ósea realizada en el pubis.

clasificación del grado histológico se muestra en la Tabla 1. En nuestro caso se trataba de un condrosarcoma de bajo grado I.

Respecto al tratamiento, como regla general se realiza una resección tumoral ampliada multisegmentaria (eliminación de la zona reactiva y tejido sano circundante $-3 \mathrm{~cm}$ aproximadamente- en función de los límites anatómicos y la experiencia del cirujano) según la extensión de la infiltración tumoral basándonos en la clasificación de Enneking. ${ }^{3}$ En nuestro caso se decide resección unisegmentaria ampliada sobre el segmento 3 sin reconstrucción ósea dada la localización, segmento anatómico y grado de malignidad. No es infrecuente que los condrosarcomas de pelvis afecten la pelvis renal invadiendo sus estructuras, ${ }^{8}$ por lo que el tratamiento multidisciplinar de estos tumores es habitual, teniendo que recurrir a cirujanos urológicos con cierta frecuencia en estos casos. ${ }^{9}$
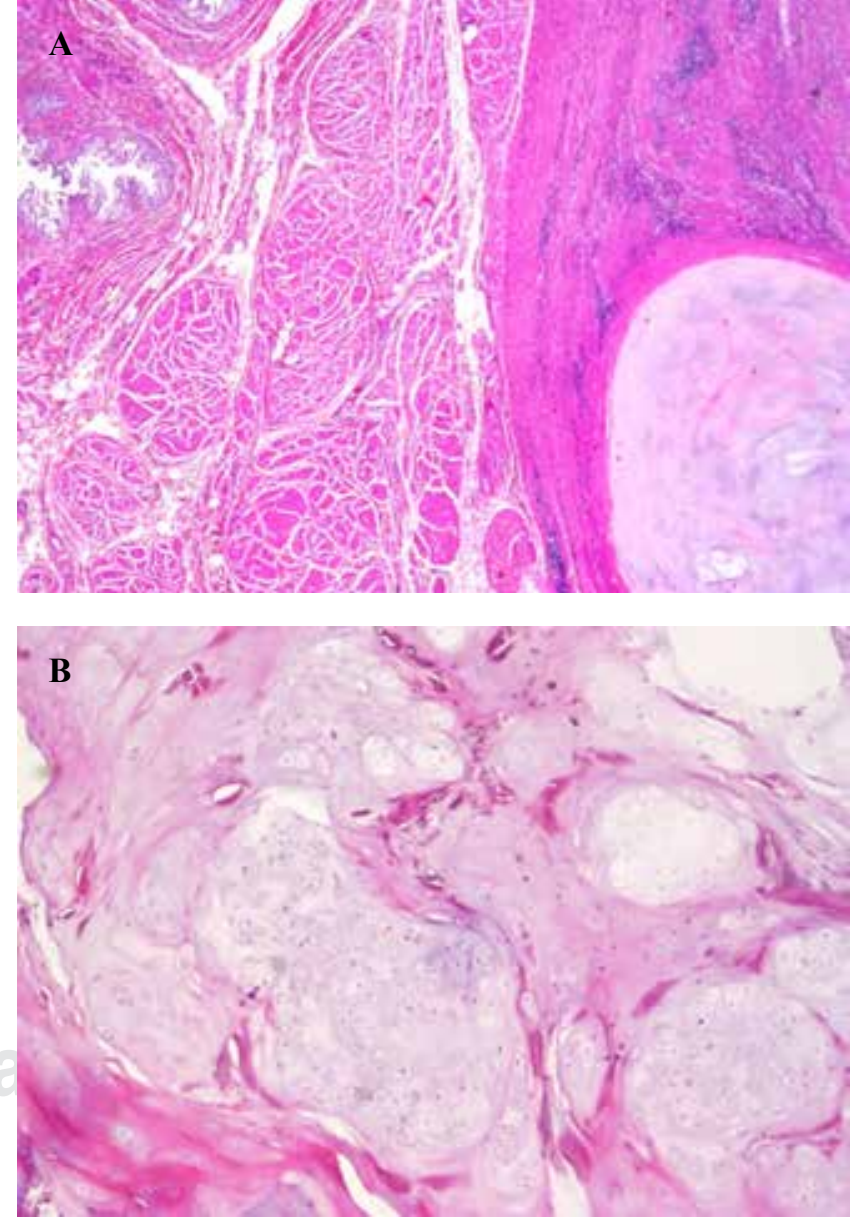

Figura 10: A) Se aprecia a la izquierda la pared vesical sin signos de malignidad celular. A la derecha se aprecia la infiltración focal de esta pared por una masa tumoral de arquitectura nodular y aspecto cartilaginoso con áreas de calcificación. B) Se aprecian células con morfología lobular, cartilaginosas, citoplasma claro, algunas polinucleadas. Celularidad y atipia escasas, lo que evidencia un condrosarcoma de grado I. 
El uso de prótesis tumorales, injerto óseo u osteosíntesis son técnicas de reconstrucción utilizadas cuando el condrosarcoma asienta en extremidades o articulaciones. ${ }^{3}$

No se ha demostrado que la quimioterapia sea eficaz en este tipo de tumor y la radioterapia tiene un papel secundario, reservándose para casos de recurrencia o en lugares específicos en tumores de bajo grado. . $^{3,4,10}$

Los resultados funcionales dependen del tamaño del tumor, su localización y el remanente de partes blandas postquirúrgico para la cobertura. ${ }^{3}$

Pensamos que es fundamental el manejo de estos casos en un comité de tumores multidisciplinar, siendo necesario realizar la intervención quirúrgica de forma conjunta con el resto de especialidades quirúrgicas involucradas.

Referencias

1. Mavrogenis AF, Angelini A, Drago G, Merlino B, Ruggieri P. Survival analysis of patients with chondrosarcomas of the pelvis. J Surg Oncol. 2013; 108(1): 19-27.

2. Arora RS, Alston RD, Eden TOB, Geraci M, Birch JM. The constrating age incidence patterns of bone tumors in teenagers and young adults: implications for aetiology. Int J Cancer. 2012; 131: 1678-85.

3. Guder WK, Hardes J, Gosheger G, Nottrott M, Streitbürger A. Osteound chondrosarkome des beckens und der unteren extremitäten. Der Chirurg. 2015; 86: 993-1003.

4. González-Pérez AM, Arvinius C, García-Coiradas J, García-Maroto R, Cebrian-Parra JL. Surgical treatment of malignant primary tumors of the pelvis on Ennekings zone II. Acta Ortop Mex. 2016; 30(3): 132-7.

5. Martínez TFJ, Manjón LP, Montes MS. Condrosarcoma. Variantes de condrosarcoma. Rev Esp Patol. 2006; 39: 69-79.
6. Enneking WF, Spanier SS, Goodman MA. A system for the surgical staging of musculoskeletal sarcoma. Clin Orthop Rel Res. 1980; 153: 106-20.

7. Zhang XP, Zheng Q, Wang C, Wang L, Liu Y, Li QC, et al. Carcinosarcoma of the renal pelvis with prominent heterologous elements mimicking teratoma: a case report and literature review. Int $J$ Clin Exp Med. 10.8 2017: 12676-81.

8. Chen D, Ye ZI, Wu X, Shi B, Zhou L, Sun S, et al. Primary mesenchymal chondrosarcoma with bilateral kidney invasion and calcification in renal pelvis: a case report and review of the literature. Oncol Lett. 2015; 10(2): 1075-8.

9. Kumar S, Sarkar D, Prasad S, Gupta V, Ghosala P, Kaman L, et al. Large pelvic masses of obscure origin: urologist's perspective. Urol Int. 2012; 88(2): 215-24.

10. Arnal-Burró J, Calvo-Haro JA, Igualada-Blazquez C, Gil-Martínez P, Cuervo-Dehesa M, Vaquero-Martín J. Hemipelvectomy for the treatment of high-grade sarcomas: pronostic of chondrosarcomas compared to other histological types. Rev Esp Cir Ortop Traumatol. 2016; 60(1): 67-74.

Protección de personas y animales: Los autores declaran que para esta investigación no se han realizado experimentos en seres humanos ni en animales.

Confidencialidad de los datos: Los autores declaran que han seguido los protocolos de su centro de trabajo sobre la publicación de datos de pacientes.

Derecho a la privacidad y consentimiento informado: Los autores declaran que en este artículo no aparecen datos de pacientes.

Conflicto de intereses: Los autores declaran no tener ningún conflicto de intereses.

Financiamiento: Los autores declaran no haber realizado gasto monetario alguno para la realización de este estudio. 